\title{
Corrigendum to "Experiment on Seepage Property and Sand Inrush Criterion for Granular Rock Mass"
}

\author{
Kai Zhang $\mathbb{D}^{1,2}$ Boyang Zhang $\mathbb{D}^{3},^{3}$ Jiangfeng Liu $\mathbb{D}^{1,2}$ Dan Ma $\mathbb{D}^{4},{ }^{4}$ and Haibo Bai $\mathbb{D}^{1,2}$ \\ ${ }^{1}$ State Key Laboratory for Geomechanics and Deep Underground Engineering, China University of Mining \& Technology, \\ Xuzhou 221116, China \\ ${ }^{2}$ School of Mechanics and Civil Engineering, China University of Mining \& Technology, Xuzhou 221116, China \\ ${ }^{3}$ School of Civil Engineering, Henan Polytechnic University, Jiaozuo 454000, China \\ ${ }^{4}$ School of Resources \& Safety Engineering, Central South University, Changsha 410083, China \\ Correspondence should be addressed to Boyang Zhang; zhangboyang@hpu.edu.cn
}

Received 9 May 2018; Accepted 16 May 2018; Published 5 July 2018

Copyright (c) 2018 Kai Zhang et al. This is an open access article distributed under the Creative Commons Attribution License, which permits unrestricted use, distribution, and reproduction in any medium, provided the original work is properly cited.

In the article titled "Experiment on Seepage Property and Sand Inrush Criterion for Granular Rock Mass" [1], there was an error in the Acknowledgments section, which should be corrected as follows:

The authors acknowledge the financial support by the Fundamental Research Funds for the Central Universities (2015XKZD06) and the Natural Science Foundation of Jiangsu Province of China (BK20160249).

\section{References}

[1] K. Zhang, B. Zhang, J. Liu, D. Ma, and H. Bai, "Experiment on seepage property and sand inrush criterion for granular rock mass," Geofluids, vol. 2017, Article ID 9352618, 10 pages, 2017. 

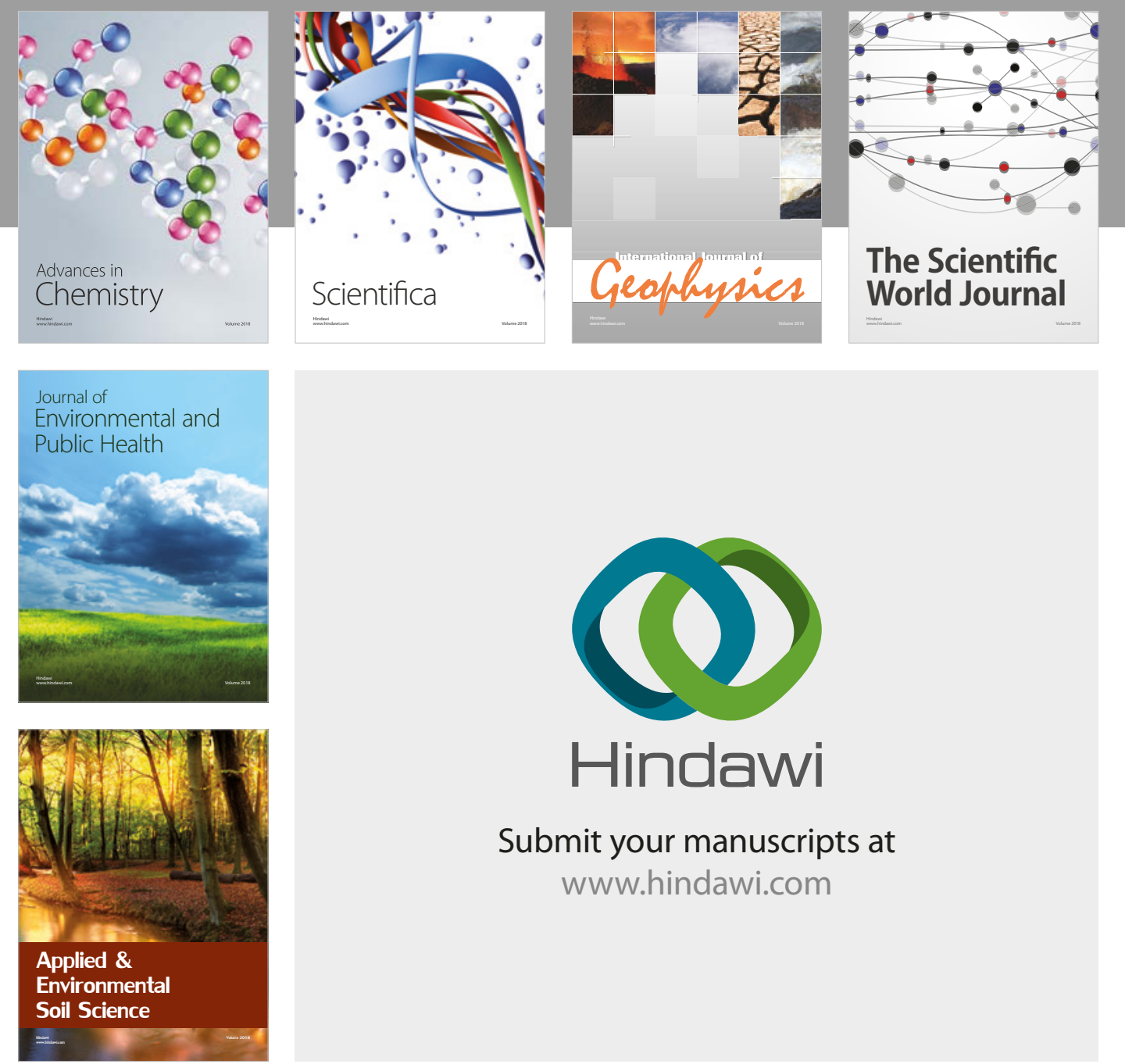

The Scientific

\section{World Journal}
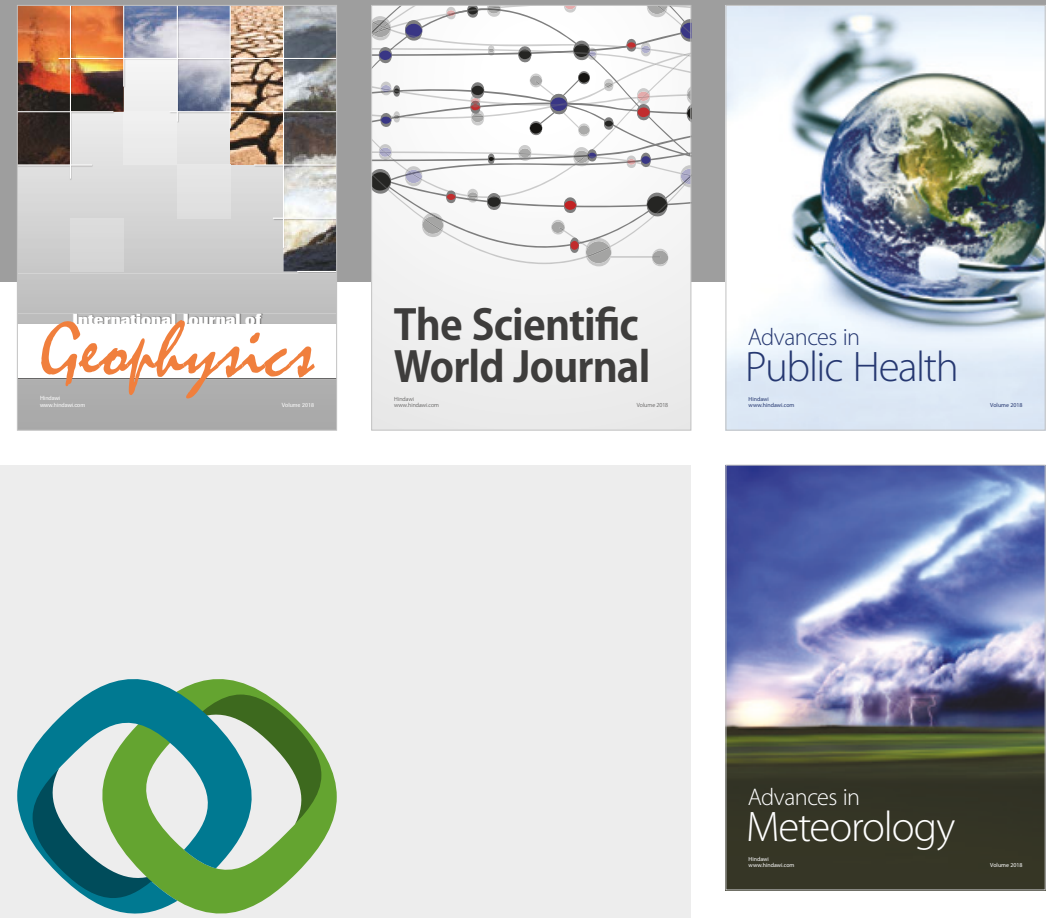

Advan

Public Health

\section{Hindawi}

Submit your manuscripts at

www.hindawi.com
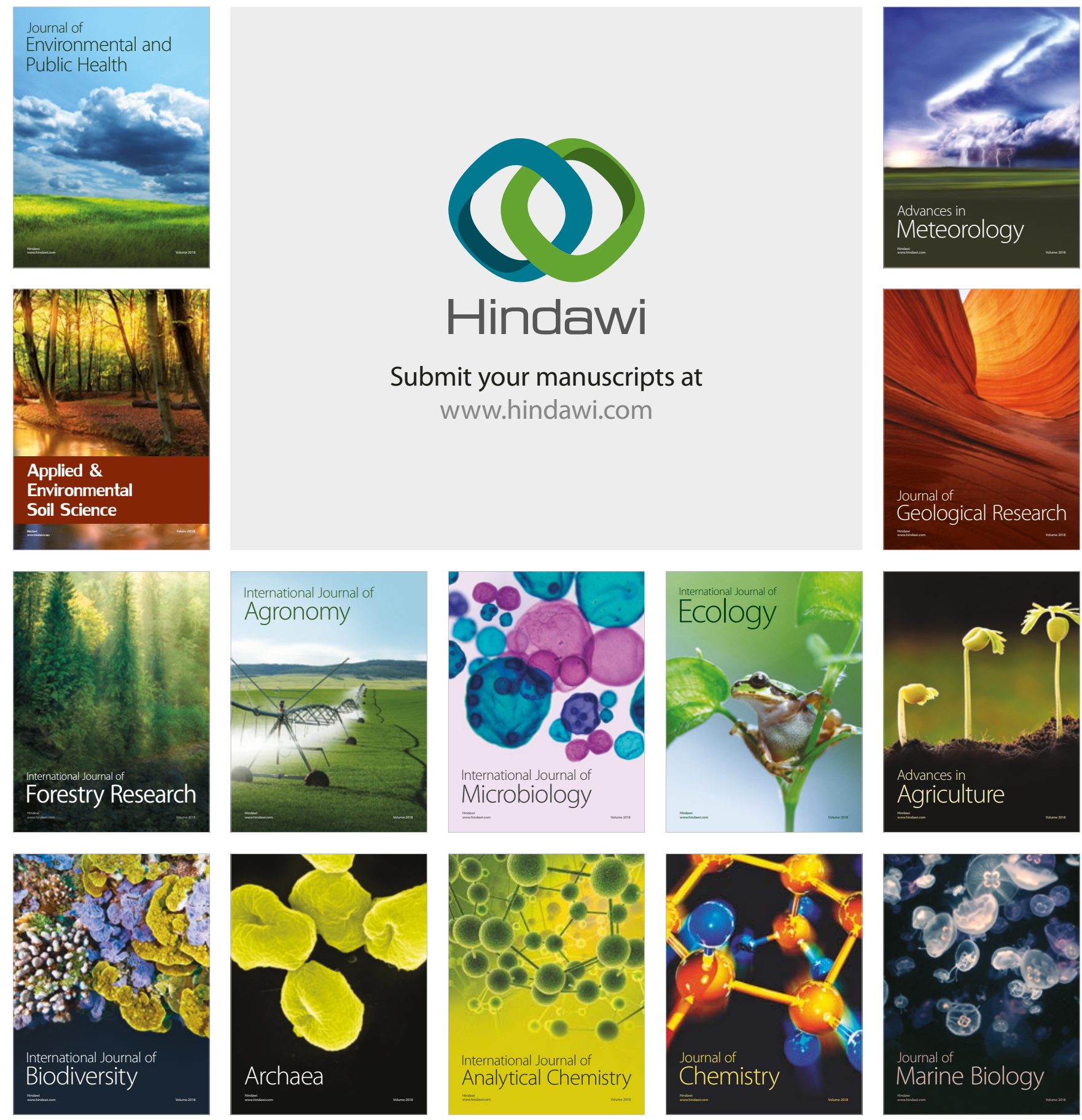